Ветеринарная вирусология, микробиология, паразитология

УДК 636.22/.28:619:578.831.31:577.2

doi: 10.15389/agrobiology.2021.4.695rus

\title{
ВЫЯВЛЕНИЕ И КОЛИЧЕСТВЕННАЯ ОЦЕНКА ВИРУСНЫХ И БАКТЕРИАЛЬНЫХ ВОЗБУДИТЕЛЕЙ РЕСПИРАТОРНЫХ БОЛЕЗНЕЙ КРУПНОГО РОГАТОГО СКОТА ПРИ ПОМОЩИ ПЦР В РЕАЛЬНОМ ВРЕМЕНИ
}

\author{
А.В. НЕФЕДЧЕНКО, А.Г. ГЛОТОВ, С.В. КОТЕНЕВА, Т.И. ГЛОТОВА
}

Респираторные болезни крупного рогатого скота (КРС) широко распространены во всех странах с развитым животноводством и наносят значительный экономический ущерб. Часто они являются результатом синергического взаимодействия нескольких вирусов и бактерий, преимущественно семейства Pasteurellaceae. Клинические признаки и патологоанатомические изменения внутренних органов зависят от наличия или отсутствия того или иного возбудителя. Массовые вспышки возникают при объединении животных из разных источников. Этиологическая структура таких вспышек достаточно изучена, однако данных, касающихся особенностей распределения бактерий и вирусов в органах респираторного тракта и их количественного определения, недостаточно. Нами представлены результаты изучения этиологической структуры вспышки респираторных болезней в условиях молочного комплекса после ввода КРС из-за рубежа, во время которой пало более 400 животных разных половозрастных групा. Исследовали пробы внутренних органов 58 павших животных разного возраста. При изучении этиологической структуры вспышки использовали стандартные бактериологические методы, вирусные агенты идентифицировали в ПЦР методом гель-электрофореза, а для количественной оценки всех обнаруженных инфекционных агентов применили ПЦР в режиме реального времени. Всего выявили 9 вирусов и бактерий, из которых респираторно-синцитиальный вирус KPC (BRSV, Bovine Respiratory Syncytial Virus, род Pneumovirus, семейство Paramyxoviridae) и бактерии семейства Pasteurellaceaе играли ведущую этиологическую роль. С использованием количественной ПЦР определили концентрации вируса и бактерий Pasteurella multocida и Mannheimia haemolytica в органах респираторного тракта 13 телят разного возраста со сходными клиническими признаками, патологоанатомическими изменениями и присутствием в органах респираторного тракта трех возбудителей. Концентрация агентов составляла от 0,1 $\pm 0,03$ до 4,8 $\pm 0,47 \log _{10}$ геномных эквивалентов (ГЭ)/мл для BRSV, от $1,3 \pm 0,60$ до

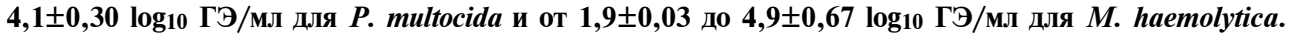
Концентрация и распространение возбудителей по органам у телят разных возрастов различались. BRSV выявили в более широком диапазоне органов дыхания как свободных от бактерий, так и колонизированных ими. В легких концентрация вируса была выше, чем в трахеальном и бронхиальном экссудате. $P$. multocida присутствовала только в верхних и средних долях легких у 2,5-4месячных телят в приблизительно равных концентрациях при острой форме бронхопневмонии. Степень колонизации легких этой бактерией повышалась с возрастом, и у телят в возрасте 6 мес ее численность достигала максимальных значений в верхних и средних долях легких, легочных лимфатических узлах и смывах со слизистых оболочек при хронической бронхопневмонии. M. haemolytica выявляли при острой форме бронхопневмонии у телят в возрасте 2,5 мес в минимальном количестве в средних долях легких, в максимальном - в трахеальном и бронхиальном экссудатах. Результаты показали, что вирус и бактерии размножаются в различных частях легких, не подавляя друг друга, что подтверждает эффект их синергического взаимодействия и приводит к усилению тяжести течения пневмонии. Количественная оценка вирусов и бактерий методом ПЦР в режиме реального времени может быть полезным инструментом для изучения патогенеза смешанных вирусно-бактериальных инфекций в естественных условиях. Полученные результаты подчеркивают роль вируса в возникновении легочного пастереллеза.

Ключевые слова: крупный рогатый скот, респираторные инфекции, ПЦР в режиме реального времени, количественный анализ, респираторно-синцитиальный вирус, Pasteurella multocida, Mannheimia haemolytica, синергизм.

Респираторные болезни крупного рогатого скота (КРС) широко распространены во всех странах с развитым животноводством и наносят значительный экономический ущерб $(1,2)$. Как правило, эти патологии - peзультат синергического взаимодействия нескольких вирусов и бактерий семейства Pasteurellaceae. К возбудителям вирусной природы относятся вирус инфекционного ринотрахеита (ИРТ КРС, BoHV-1 - Bovine Herpes Virus-1, синоним Вovine alphaherpesvirus 1, род Varicellovirus, семейство Herpesviridae), вирус вирусной диареи КРС трех типов (ВД-БС КРС, BVDV1-3 - 
Bovine Viral Diarrhea Virus 1-3, синоним Pestivirus A, В и Н, род Pestivirus, семейство Flaviviridae), вирус парагриппа КРС 3-го типа (ПГ-3 КРС, BPIV3 - Bovine Parainfluenza Virus-3, синоним Bovine Respirovirus 3, род Respirovirus, семейство Paramyxoviridae), коронавирус (КВ КРС, ВCoV - Bovine Corona Virus, род Betacoronavirus, семейство Coronaviridae) и некоторые другие $(3,4)$. В практических условиях могут возникать различные ассоциации вирусов и бактерий с преобладанием или, наоборот, отсутствием какого-то возбудителя, что влияет на тяжесть течения болезни и характер патологоанатомических изменений (5). Часто такие вспышки происходят при комплектовании хозяйств сборным поголовьем, в том числе после завоза животных из-за рубежа.

Респираторно-синцитиальный вирус КРС (РСВ КРС, Bovine respiratory syncytial virus, род Orthopneumovirus, семейство Pneumoviridae) - один из этиологических агентов респираторного комплекса КРС (6-9). К инфицированию восприимчивы животные всех возрастов и пород (10). Вирус может вызывать бронхиты, интерстициальную пневмонию и эмфизему легких самостоятельно, но главное его свойство - формирование предрасположенности к бактериальным пневмониям $(11,12)$. Описано синергическое взаимодействие вируса и бактерий Pasteurella multocida, Mannheimia haemolytica, Histophilus somni (12-16).

Сведения о накоплении респираторно-синцитиального вируса в разных отделах респираторного тракта естественно инфицированных животных, в том числе одновременно с бактериями $P$. multocida, M. haemolytica, в литературе отсутствуют. Проведение таких исследований позволит расширить объем сведения о роли BRSV в возникновении и развитии смешанных вирусно-бактериальных инфекций у крупного рогатого скота. Возможно, вирус не только служит пусковым фактором, но может размножаться в органах и тканях на фоне бактерий независимо от них.

Новизна представленных нами результатов заключается в получении новых данных о выявлении и определении концентрации геномов BRSV и бактерий P. multocida, M. haemolytica в органах респираторного тракта животных при массовой вспышке респираторных болезней на крупном молочном комплексе после завоза животных из-за рубежа.

Целью работы было изучение этиологической структуры массовой вспышки респираторной инфекции у КРС в ограниченной популяции животных и определение концентрации геномов BRSV и бактерий P. multocida, M. haemolytica в органах респираторного тракта крупного рогатого скота при помощи количественной ПЦР в режиме реального времени.

Методика. Для исследований отбирали пробы выделений из носа, экссудата трахеи и бронхов, слизистой оболочки трахеи и крупных бронхов, легочных лимфатических узлов и различных частей легких от 58 животных разного возраста голштинской породы, павших через 7-14 сут после появления первых клинических признаков. Образцы отбирали в течение 2 ч после гибели животных, немедленно замораживали и доставляли в лабораторию в течение 12 ч. Всего отобрали 464 пробы биоматериала. Мониторинг заболеваемости среди поголовья молочного комплекса проводили в течение 2 лет.

Подготовка проб для исследований описана нами ранее $(17,18)$. Образцы подвергали немедленной заморозке и доставляли в лабораторию, где делили на две части. Первую немедленно исследовали на наличие инфекционных агентов, вторую хранили при $-80{ }^{\circ} \mathrm{C}$ для последующего определения концентрации патогенных микроорганизмов.

После оттаивания гомогенизированные образцы центрифугировали 
при 10000 об/мин в течение 5 мин, 100 мкл осветленного супернатанта использовали для выделения РНК и ДНК согласно описанию $(17,18)$. На первом этапе при изучении этиологической структуры вспышки вирусные агенты идентифицировали в ПЦР методом гель-электрофореза с использованием пар праймеров и параметров постановки ПЦР, опубликованных ранее для BoHV-1 (17), BVDV-1 и BVDV-2 (18), BRSV (19), BPIV-3 (20), $\mathrm{BCoV}(21)$.

Бактериологические исследования проводили в соответствии с Руководством МЭБ (ОІЕ) (Международное эпизоотическое бюро) (22). Бактерии выделяли на искусственных питательных средах - кровяном мясопептонном агаре (КМПА), агаре на основе мясного перевара по Хоттингеру с добавлением 10 \% сыворотки крови лошади и типировали в ПЦР с использованием праймеров согласно описанию (23-25).

Обратную транскрипцию проводили с использованием набора реагентов Реверта-L (ФБУН ЦНИИ Эпидемиологии Роспотребнадзора, Россия) в соответствии с рекомендациями производителя.

Для количественного определения BRSV, P. multocida и M. haemolytica в РТ-ПЦР исследовали 104 образца биоматериала, хранившиеся при $-80{ }^{\circ} \mathrm{C}$, в которых по результатам предварительных исследований были выявлены только эти три возбудителя одновременно.

Постановку количественной РT-ПЦР (RT-qPCR) проводили в 30 мкл смеси, содержащей 5 мкл кДНК или ДНК, 0,1 мкМ каждого праймера и зонда, рекомендуемых для анализируемых патогенов (26-28), готовую смесь реагентов BioMaster PCR-RV («Биолабмикс», Россия). Программа амплификации: 5 мин при $95{ }^{\circ} \mathrm{C}$, затем 45 циклов: 15 с при $95{ }^{\circ} \mathrm{C}$, 1 мин при $60{ }^{\circ} \mathrm{C}$. Реакции проводили на амплификаторе Real-time CFX96 Touch («Bio-Rad», CША).

Положительные контрольные образцы (ПКО) были получены нами с применением набора TA Cloning ${ }^{\circledR}$ Kit with pCR ${ }^{\mathrm{TM}} 2.1$ vector («Invitrogen», США) посредством клонирования фрагментов генов $N$ BRSV, gapdh KРC, kmt1 P. multocida и sodA M. haemolytica в клонирующий вектор $\mathrm{pCR}^{\mathrm{TM}}$ 2.1. Концентрацию ПКО определяли с помощью набора Quant-iT ${ }^{\mathrm{TM}}$ dsDNA Assay Kit, HS («Invitrogen», США) и флуориметра QUBIT 4 («Invitrogen», США) и пересчитывали в число копий (программа-конвертер http://molbiol.ru/scripts/01_07.html). ПКО добавляли в объеме 5 мкл на peакцию. Источниками фрагментов генов (контроли специфичности ПЦР) служили штаммы РСБ BRSV, 1231 P. multocida и S1-16 M. haemolytica, полученные из коллекции культур микроорганизмов ФГБНУ ФНЦ ВИЭВ РАН. Эти же штаммы использовали при оценке чувствительности и воспроизводимости реакций с расчетом коэффициента детерминации $\mathrm{R}^{2}$.

Для расчета количества РНК и ДНК патогенов в образце строили стандартную кривую амплификации с 10-кратными разведениями ПКО с известной концентрацией. Количество PHK BRSV и ДНК бактерий в образцах оценивали на основе сравнения Ct (Cycle threshold - пороговый цикл) образца со стандартной кривой и выражали в виде $\log _{10}$ геномных эквивалентов (ГЭ) (вирусной РНК или бактериальной ДНК) на 1 мл суспензии $\left(\mathrm{N} \log _{10}\right.$ ГЭ/мл) и нормализовали относительно $10^{5}$ ГЭ гена gapdh КРС в соответствии с ранее описанной методикой (29).

Определение чувствительности количественной РТ-ПЦР проводили в трех повторах.

Полученные результаты подвергали статистической обработке при помощи программы Statistica 8 («StatSoft, Inc.», США). Для показателей 
рассчитывали средние $(M)$ и стандартные ошибки средних ( $\pm \mathrm{SEM})$.

Результаты. Исследования проводили в условиях молочного комплексе с поголовьем 1080 коров голштинской породы со среднегодовой продуктивностью более 7000,00 л во время вспышки респираторного заболевания среди животных всех возрастов после завоза импортного скота. На момент исследования вакцинация против вирусных заболеваний не проводилась. Животные находились круглогодично на стойловом содержании в соответствии с физиологическими и зоотехническими нормами.

В 2016 году в хозяйство были завезены 752 высокопродуктивных нетели из-за рубежа. Они размещались отдельно от местного поголовья, но без соблюдения режима строгого карантина, в период которого клинические признаки болезни были выявлены у 40 завезенных животных (5,3 \%), из которых 10 (1,3 \%) пали с диагнозом острая фибринозная пневмония. В течение 2017 года от завезенных нетелей было получено 700 телят, из которых 160 (22,8 \%) пали до достижения возраста 30 сут с тем же диагнозом. Через 1 мес клинические признаки болезни были обнаружены у местных животных, в частности у телят в возрасте от 1 до 6 мес. Из 600 телят 490 $(81,6 \%)$ заболели и $240(48,9 \%)$ пали. Одновременно с телятами заболевание было выявлено у 400 местных коров, падеж и вынужденный убой которых составил 30 гол. (7,5 \%). Телята в возрасте от 10 сут до 1 мес болели реже. При клиническом осмотре у больных животных регистрировали угнетение, отказ от корма, повышение температуры тела, учащенное дыхание брюшного типа с открытым ртом и высунутым языком, опущенные вниз шею и голову, обильные выделения пены из ротовой полости. У местных телят посмертным диагнозом была острая катарально-фибринозная бронхопневмония. В легких выявляли лабарную пневмонию с поражением передневентральных участков в виде красной гепатизации у телят до 2,5 мес и серой гепатизации у телят старших возрастов. Междольковые перегородки (септы) были отечными, пропитаны студенистым экссудатом и содержали фибрин. Ткань легких на разрезе была геморрагически воспаленной и уплотненной, с участками некроза. В некоторых случаях регистрировали отек и эмфизему легких.

1. Пары праймеров и параметры постановки ПЦР, использованные для выявления вирусов в пробах биоматериала от павших животных голштинской породы разного возраста при массовой вспышке респираторных болезней (Новосибирская обл., 2017 год)

\begin{tabular}{|c|c|c|c|c|c|}
\hline $\begin{array}{l}\text { Возбу- } \\
\text { дитель }\end{array}$ & Ген & Последовательность $\left(5^{\prime} \rightarrow 3^{\prime}\right)$ & $\begin{array}{l}\text { Программа } \\
\text { амплификации }\end{array}$ & $\left|\begin{array}{l}\text { Размер } \\
\text { фрагмента, } \\
\text { П.н. }\end{array}\right|$ & $\begin{array}{l}\text { Ссыл- } \\
\text { ка }\end{array}$ \\
\hline$\overline{\mathrm{BoHV}}-1$ & $g B$ & $\begin{array}{l}\text { ACGTGCTGCTCAACGTGTAC } \\
\text { AGGACGAGCTCGCGGATATA }\end{array}$ & $\begin{array}{l}95{ }^{\circ} \mathrm{C} 5 \text { мин; } 95^{\circ} \mathrm{C} 1 \text { мин, } \\
54^{\circ} \mathrm{C} 1 \text { мин, } 72^{\circ} \mathrm{C} 1,5 \text { мин } \\
\left(35 \text { повторов); } 72^{\circ} \mathrm{C} 5 \text { мин }\right.\end{array}$ & 464 & (17) \\
\hline BVDV-1 & NS5B & GAGATCTTTCACACAATAGCTG & $95^{\circ} \mathrm{C} 5$ мин; $95^{\circ} \mathrm{C} 45 \mathrm{c}, 60^{\circ} \mathrm{C}$ & 356 & (18) \\
\hline BVDV-2 & & $\begin{array}{l}\text { GAACCTAAGAACTAAATCGG } \\
\text { TGTTTCACCCAGTTATACATGC }\end{array}$ & $\begin{array}{l}45 \mathrm{c}, 72^{\circ} \mathrm{C} 1 \text { мин ( } 35 \text { повто- } \\
\text { ров); } 72{ }^{\circ} \mathrm{C} 5 \text { мин }\end{array}$ & 586 & \\
\hline BRSV & $g F$ & $\begin{array}{l}\text { CATCAATCCAAAGCACCACACTGTC } \\
\text { GCTAGTTCTGTGGTGGATTGTTGTC }\end{array}$ & $\begin{array}{l}95^{\circ} \mathrm{C} 5 \text { мин; } 95^{\circ} \mathrm{C} 30 \mathrm{c}, 60^{\circ} \mathrm{C} \\
30 \mathrm{c}, 72^{\circ} \mathrm{C} 45 \mathrm{c}(35 \text { повто- } \\
\text { ров); } 72^{\circ} \mathrm{C} 5 \text { мин }\end{array}$ & 371 & (19) \\
\hline BPIV-3 & $M$ gene & $\begin{array}{l}\text { GATCAGGAACTCTTAAAGGC } \\
\text { TTTTCCCGACCCCTTCTAT }\end{array}$ & $\begin{array}{l}95^{\circ} \mathrm{C} 5 \text { мин; } 95^{\circ} \mathrm{C} 15 \mathrm{c}, 57^{\circ} \mathrm{C} \\
25 \mathrm{c}, 72^{\circ} \mathrm{C} 30 \text { с }(40 \text { повто- } \\
\text { ров); } 72{ }^{\circ} \mathrm{C} 5 \text { мин }\end{array}$ & 739 & (20) \\
\hline $\mathrm{BCoV}$ & $N$ gene & $\begin{array}{l}\text { GCCGATCAGTCCGACCAATC } \\
\text { AGAATGTCAGCCGGGGTAT }\end{array}$ & $\begin{array}{l}95^{\circ} \mathrm{C} 5 \text { мин; } 95^{\circ} \mathrm{C} 30 \mathrm{c}, 55^{\circ} \mathrm{C} \\
30 \mathrm{c}, 72{ }^{\circ} \mathrm{C} 45 \text { с }(35 \text { повто- } \\
\text { ров); } 72{ }^{\circ} \mathrm{C} 5 \text { мин }\end{array}$ & 407 & (21) \\
\hline
\end{tabular}

На первом этапе при изучении этиологической структуры вспышки вирусные агенты идентифицировали в ПЦР с разделением методом гель- 
электрофореза с использованием праймеров и параметров постановки реакции (18-21, 23-25) (табл. 1, 2).

2. Пары праймеров и параметры постановки ПЦР, использованные для типирования бактерий, выделенных на искусственных питательных средах в пробах биоматериала от павших животных голштинской породы разного возраста при массовой вспышке респираторных болезней (Новосибирская обл., 2017 год)

\begin{tabular}{|c|c|c|c|c|c|}
\hline Возбудитель & Ген & Последовательность $\left(5^{\prime} \rightarrow 3^{\prime}\right)$ & $\begin{array}{l}\text { Программа } \\
\text { амплификации }\end{array}$ & $\begin{array}{l}\text { Размер } \\
\text { фрагмен- } \\
\text { та, пн }\end{array}$ & $\begin{array}{l}\text { Ссыл- } \\
\text { ка }\end{array}$ \\
\hline $\begin{array}{l}\text { Mannheimia } \\
\text { haemolytica }\end{array}$ & $\operatorname{sod} A$ & $\begin{array}{l}\text { GACTACTCGTGTTGGTTCAGGCT } \\
\text { CGGATAGCCTGAAACGCCT }\end{array}$ & $95^{\circ} \mathrm{C} 5$ мин; $95^{\circ} \mathrm{C} 15 \mathrm{c}, 57^{\circ} \mathrm{C}$ & 126 & (23) \\
\hline $\begin{array}{l}\text { Pasteurella } \\
\text { multocida }\end{array}$ & kmtl & $\begin{array}{l}\text { ATAAGAAATAACTCAACATGGAAAT } \\
\text { GAGTGGGCTTGTCGGTAGTCTT }\end{array}$ & ров); $72^{\circ} \mathrm{C} 5$ мин & 211 & (23) \\
\hline Mycobacterium & $u r v C$ & TTACGCAAGAGAATGCTTCA & $95^{\circ} \mathrm{C} 5$ мин; $95^{\circ} \mathrm{C} 15 \mathrm{c}, 52^{\circ} \mathrm{C}$ & 1600 & (24) \\
\hline bovis & & TAGGAAAGCACCCTATTGAT & $\begin{array}{l}20 \mathrm{c}, 72{ }^{\circ} \mathrm{C} 30 \text { с (45 повто- } \\
\text { ров); } 72{ }^{\circ} \mathrm{C} 5 \text { мин }\end{array}$ & & \\
\hline $\begin{array}{l}\text { Histophilus } \\
\text { somni }\end{array}$ & $\begin{array}{l}16 S \\
r D N A\end{array}$ & $\begin{array}{l}\text { GAAGGCGATTAGTTTAAGAG } \\
\text { TTCGGGCACCAAGTRTTCA }\end{array}$ & $\begin{array}{l}94^{\circ} \mathrm{C} 5 \text { мин, } 95^{\circ} \mathrm{C} 1 \text { мин, } 55^{\circ} \mathrm{C} \\
1 \text { мин, } 72^{\circ} \mathrm{C} 1 \text { мин }(35 \text { по- } \\
\text { второв); } 72^{\circ} \mathrm{C} 5 \text { мин }\end{array}$ & 397 & (25) \\
\hline
\end{tabular}

В результате бактериологических исследований от большинства животных выделяли и типировали M. haemolytica $(53,4 \%)$ и $P$. multocida $(60,3 \%)$, реже - H. somni (12,3\%) и Mycobacterium bovis (6,9\%). В органах павших животных выявили пять вирусов, среди которых преобладал BRSV $(65,5 \%)$, реже присутствовали BCoV $(22,4 \%)$ и BPIV-3 (20,7 \%). BoHV-1 и BVDV-1 выявляли редко (соответственно у 6,9 и 8,6 \% особей). У 27 животных обнаружили BRSV и BCoV: у четырех телят в моноварианте, у 23 животных в ассоциации двух или трех вирусов (табл. 3).

3. Частота выявления (число/\%) возбудителей респираторных инфекций в пробах биоматериала от павших животных голштинской породы разного возраста при массовой вспышке респираторных болезней (Новосибирская обл., 2017 год)

\begin{tabular}{|c|c|c|c|c|c|c|c|c|c|c|c|}
\hline $\begin{array}{l}\text { Возрастная } \\
\text { группа }\end{array}$ & $\begin{array}{l}\text { Число } \\
\text { живот- } \\
\text { ных }\end{array}$ & $\frac{\vec{n}}{n}$ & $\underset{\infty}{\mathbf{m}}$ & 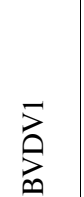 & 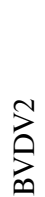 & $\frac{2}{\infty}$ & ن & 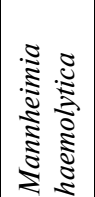 & 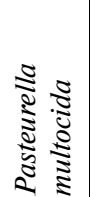 & 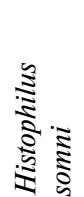 & 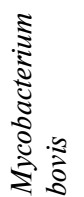 \\
\hline Теляา & 16 & $11 / 68,8$ & $1 / 6,3$ & $5 / 12,5$ & 0 & $1 / 6,3$ & $7 / 31,2$ & $3 / 18,75$ & $12 / 75,0$ & 0 & $1 / 6,25$ \\
\hline Телят & 10 & $10 / 100,0$ & 0 & 0 & 0 & $1 / 10,0$ & $4 / 40,0$ & $7 / 70,0$ & $7 / 70,0$ & $2 / 20,0$ & 0 \\
\hline Телята 4-6 мес & 12 & $12 / 100,0$ & 0 & 0 & 0 & $2 / 16,7$ & $2 / 16,7$ & $9 / 75,0$ & $8 / 66,7$ & $1 / 8,3$ & 0 \\
\hline Нетели & 10 & $2 / 20,0$ & $3 / 30,0$ & 0 & 0 & $5 / 50,0$ & 0 & $5 / 50,0$ & $3 / 30,0$ & $3 / 30,0$ & $1 / 10,0$ \\
\hline Коровы & 10 & $3 / 30,0$ & $1 / 10,0$ & 0 & 0 & $3 / 30,0$ & 0 & $7 / 70,0$ & $5 / 50,0$ & $2 / 20,0$ & $2 / 20,0$ \\
\hline Всего & 58 & $38 / 65,5$ & $4 / 6,9$ & $5 / 8,6$ & 0 & $12 / 20,7$ & $13 / 22,4$ & $31 / 53,4$ & $35 / 60,3$ & $8 / 13,8$ & $4 / 6,9$ \\
\hline
\end{tabular}

Частота обнаружения возбудителей зависела от возраста животных. У телят в возрасте до 30 сут чаще выявляли $M$. haemolytica $(75,0 \%)$ и BRSV $(68,8 \%)$, реже $P$. multocida $(18,8 \%)$ и $\mathrm{BCoV}(18,8 \%)$. У 2-3-месячных телят частота составила для BRSV $-100 \%$, для P. multocida $-70 \%$, M. haemolytica - $70 \%$, BPIV-3 - $30 \%$. У 4-6-месячных телят BRSV присутствовал в $100 \%$, M. haemolytica - в $75 \%$ и P. multocida - в 65,7\% случаев. BCoV и BPIV-3 находили соответственно у 25,0 \% и $16,7 \%$ животных. У коров и нетелей на $20 \%$ чаще выявляли M. haemolytica, чем P. multocida. Частота обнаружения BRSV у них составила соответственно $20 \%$ и $30 \%$.

Чаще всего в пробах органов практически всех отделов респираторного тракта присутствовали три возбудителя - BRSV, M. haemolytica и P. multocida. В связи с этим с помощью количественной ПЦР мы изучили концентрацию этих инфекционных агентов в различных отделах респира- 
торного тракта, в которых были выявлены все три возбудителя. Нуклеотидные последовательности использованных для этого праймеров и зондов приведены в таблице 4 .

4. Пары праймеров и зонды, использованные в количественной РТ-ПЦР для определения концентрации основных инфекционных агентов в биоматериале от павших животных голштинской породы разного возраста при массовой вспышке респираторных болезней (Новосибирская обл., 2017 год)

\begin{tabular}{|c|c|c|c|}
\hline Мишень & Ген & Последовательность $\left(5^{\prime} \rightarrow 3^{\prime}\right)$ & Ссылка \\
\hline BRSV & $N$ & $\begin{array}{l}\text { GCAATGCTGCAGGACTAGGTATAAT } \\
\text { ACACTGTAATTGATGACCCCATTCT } \\
\text { (FAM)ACCAAGACTTGTATGATGCTGCCAAAGCA(BHQ1) }\end{array}$ & (26) \\
\hline Bos taurus & gapdh & $\begin{array}{l}\text { GATGGTGAAGGTCGGAGTGAAC } \\
\text { GTCATTGATGGCGACGATGT } \\
\text { (ROX)CTGGTCACCAGGGCTGCTT(BHQ2) }\end{array}$ & (27) \\
\hline $\begin{array}{l}\text { Pasteurella } \\
\text { multocida }\end{array}$ & kmt 1 & $\begin{array}{l}\text { ATAAGAAACGTAACTCAACATGGAAATA } \\
\text { GAGTGGGCTTGTCGGTAGTCTT } \\
\text { (FAM)AAACCGGCAAATAACAATAAGCTGA(BHQ1) }\end{array}$ & (28) \\
\hline $\begin{array}{l}\text { Mannheimia } \\
\text { haemolytica }\end{array}$ & $\operatorname{sod} A$ & $\begin{array}{l}\text { GACTACTCGTGTTGGTTCAGGCT } \\
\text { CGGATAGCCTGAAACGCCT } \\
\text { (ROX)CTGGTTAGCGGTTGAAACAACGG(BHQ2) }\end{array}$ & (28) \\
\hline
\end{tabular}

Предел обнаружения для RT-qPCR составил 12-18 геномных эквивалентов (ГЭ) на одну реакцию, или 1,08 TCID50 для BRSV и 0,15 KOE для M. haemolytica и P. multocida с коэффициентом детерминации $\left(\mathrm{R}^{2}\right)$ от 0,95 до 0,99 (табл. 5).

5. Показатели воспроизводимости и чувствительности количественной РТ-ПЦР при определении концентрации основных инфекционных агентов в биоматериале от павших животных голштинской породы разного возраста при массовой вспышке респираторных болезней (Новосибирская обл., 2017 год)

\begin{tabular}{l|l|c|c|c}
\hline \multicolumn{1}{c|}{ Патоген } & \multicolumn{1}{c|}{ Образец } & $\begin{array}{l}\text { Коэффициент } \\
\text { детерминации R }\end{array}$ & $\begin{array}{l}\text { Минимальная выявляемая } \\
\text { концентрация }\end{array}$ & $\begin{array}{l}\text { Соотношение ГЭ и } \\
\text { TCID50 или КОЕ }\end{array}$ \\
\hline BRSV & ПКО & 0,98 & 18 ГЭ & 16,6 \\
Mannheimia & Штамм RSB & 0,95 & 1,08 TCID50 & 80,0 \\
haemolytica & ШТО & 0,99 & 12 ГЭ & \\
Pasteurella & ПКО & 0,97 & 0,15 KOE & 13 ГЭ \\
multocida & Штамм 1231 & 0,99 & 0,15 KОЕ & 86,7
\end{tabular}

П р и м е ч н и е. ПКО - положительные контрольные образцы, ГЭ - геномные эквиваленты.
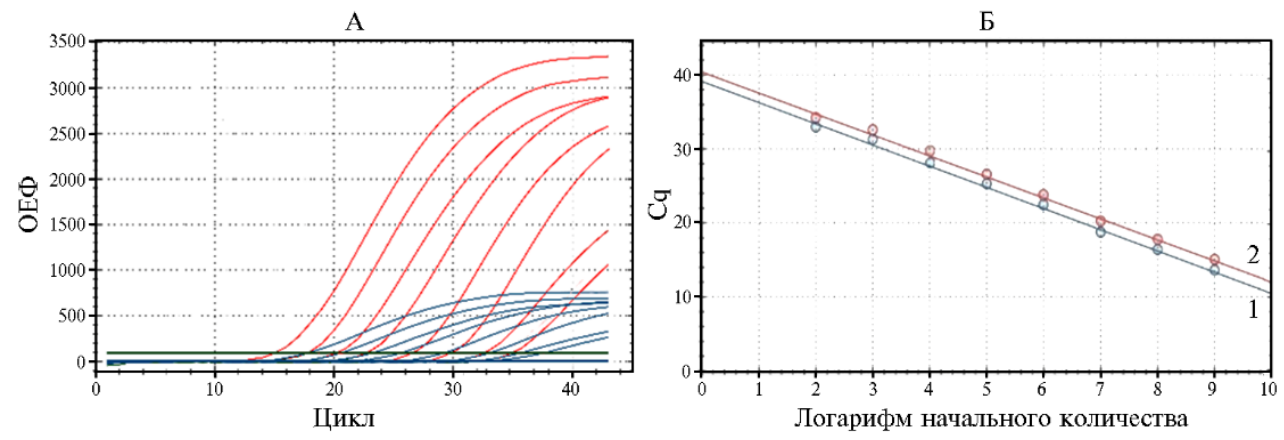

Рис. 1. График мультиплексной ПЦР (А) и динамический диапазон измерений мультиплексной ПЦР (стандартная кривая) (Б) для выявления генов $N$ BRSV и gapdh Bos taurus в биоматериале от павших животных голштинской породы разного возраста при массовой вспышке респираторных болезней (Новосибирская обл., 2017 год). А: по оси абсцисс указаны циклы ПЦР, по оси ординат - уровень флуоресценции в относительных единицах флюоресценции (ОЕФ). Б: по оси абсцисс - количество образца, $\mathrm{N} \log _{10}$ ГЭ/мл, по оси ординат - пороговый цикл Сq (О стандарт, $\times$ неизвестно, $1-$ FAM E $=123,4 \% \mathrm{R}^{2}=0,993$ уклон $=-2,865$ у-int $=39,133$, $2-\mathrm{ROX} E=125,3 \% \mathrm{R}^{2}=0,995$ уклон $=-2,835 \mathrm{y}$-int $\left.=40,377\right)$. Линии синего цвета - для зонда FAM (ген $N$ BRSV), красного цвета - для зонда ROX (gapdh Bos taurus).

График мультиплексной ПЦР для выявления генов $N$ BRSV и gapdh 
Bos taurus и динамический диапазон измерений приведены на рисунке 1, аналогичные показатели мультиплексной ПЦР для выявления генов kmt 1 P. multocida u sodA M. haemolytica - на рисунке 2.

A

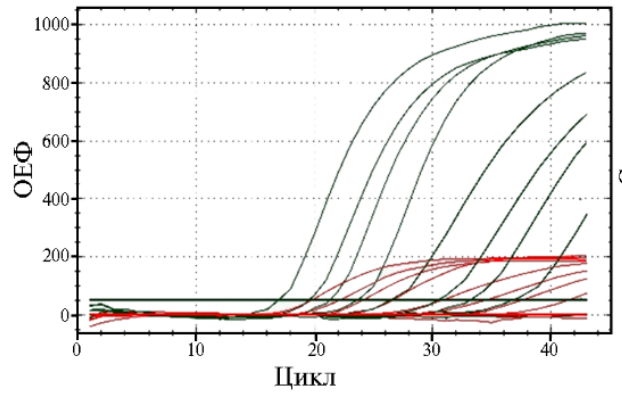

Б

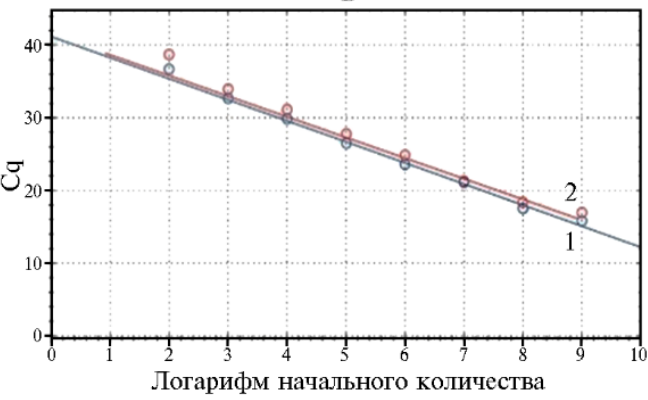

Рис. 2. График мультиплексной ПЦР (А) и динамический диапазон измерений мультиплексной ПЦР (стандартная кривая) (Б) для выявления генов kmt1 Pasteurella multocida и sodA Mannheimia haemolytica в биоматериале от павших животных голштинской породы разного возраста при массовой вспышке респираторных болезней (Новосибирская обл., 2017 год). А: по оси абсцисс указаны циклы ПЦР, по оси ординат - уровень флуоресценции в относительных единицах флюоресценции (ОЕФ). Б: по оси абсцисс - количество образца, $N \log 10$ ГЭ/мл, по оси ординат - пороговый цикл Сq (О стандарт, $\times$ неизвестно, $1-$ FAM E $=121,3 \% \mathrm{R}^{2}=0,958$ уклон $=-2,899$ y-int $=41,182,2-$ ROX E $=125,0 \% R^{2}=0,993$ уклон $=-2,839$ y-int $\left.=41,488\right)$. Линии синего цвета - для зонда FAM (ген kmt1 P. multocida), красного цвета - для зонда ROX ( $\operatorname{sodA} M$. haemolytica).

Результаты количественного определения PHK BRSV и ДНК P. multocida и M. haemolytica в образцах биоматериала от павших животных приведены в таблице 6. Из данных таблицы видно, что в образцах биоматериала от телят разных возрастов концентрация BRSV варьировала от 0,1 $\pm 0,03$ до 4,8 $\pm 0,47 \log _{10}$ ГЭ/мл, P. multocida и M. haemolytica - соответственно от $1,3 \pm 0,60$ до $4,1 \pm 0,30 \log _{10}$ и от $1,9 \pm 0,03$ до 4,9 $\pm 0,67 \log _{10}$ ГЭ/мЛ. В легких концентрация вируса была выше, чем в трахеальном и бронхиальном экссудатах, что указывает на преобладающий тропизм вируса к легочной ткани.

P. multocida присутствовала только в верхних и средних долях легких у телят в возрасте 2,5 мес (соответственно $3,1 \pm 0,22$ и 1,9 $\pm 0,39 \log _{10}$ ГЭ/мл) и

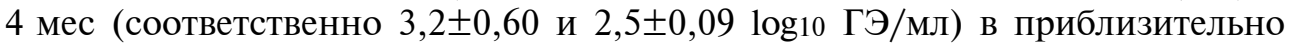
равных концентрациях. Степень колонизации легких этой бактерией повышалась с возрастом, и у 6-месячных телят концентрация бактерии достигала $3,4 \pm 0,31$ и $3,1 \pm 0,32 \log _{10}$ ГЭ/мл в верхних и средних долях легких. Кроме того, у телят этого возраста $P$. multocida была обнаружена в легочных лимфатических узлах и смывах со слизистых оболочек. Этот факт подтверждает доминирующую роль $P$. multocida в этиологии хронической бронхопневмонии у телят старших возрастов.

M. haemolytica у телят в возрасте 2,5 мес в минимальной концентрации $\left(1,9 \pm 0,03 \log _{10}\right.$ ГЭ/мл) была обнаружена в средних долях легких, а в максимальной концентрации $(4,9 \pm 0,67 \log 10$ ГЭ/мл) - в бронхиальном экссудате.

Таким образом, на основании процента случаев выявления можно сделать заключение о ведущей этиологической роли респираторно-синцитиального вируса и бактерий $M$. haemolytica и P. multocida при вспышке респираторного заболевания на молочном комплексе после завоза животных из-за рубежа. Полученные результаты подтверждают данные зарубежных исследователей о синергическом взаимодействии этого вируса и бактерий семейства Pasteurellaceae при тяжелой бронхопневмонии у животных $(1,4,14,16)$. 
6. Концентрация ( $\log 10$ ГЭ/мл суспензии) Воvine Respiratory Syncytial Virus, Pasteurella multocida, Mannheimia haemolytica в биологическом материале от телят голштинской породы разного возраста при массовой вспышке респираторных болезней на крупном животноводческом комплексе после завоза животных из-за рубежа (Новосибирская обл., 2017 год)

\begin{tabular}{|c|c|c|c|c|c|c|c|c|c|}
\hline \multirow{3}{*}{ Биоматериал } & \multicolumn{9}{|c|}{ Возрастная группа } \\
\hline & \multicolumn{3}{|c|}{$2,5 \mathrm{мес}$} & \multicolumn{3}{|c|}{4 мес } & \multicolumn{3}{|c|}{$6 \mathrm{мес}$} \\
\hline & BRSV & P. multocida & M. haemolytica & BRSV & P. multocida & M. haemolytica & BRSV & P. multocida & M. haemolytica \\
\hline \multicolumn{10}{|l|}{ Легкое: } \\
\hline краниальная доля & - & $3,1 \pm 0,22$ & $4,1 \pm 0,67$ & $3,3 \pm 0,50$ & $3,2 \pm 0,60$ & $3,3 \pm 0,46$ & - & $3,4 \pm 0,31$ & $4,4 \pm 0,46$ \\
\hline средняя доля & $4,8 \pm 0,47$ & $1,9 \pm 0,39$ & $1,9 \pm 0,03$ & $2,9 \pm 0,27$ & $2,5 \pm 0,09$ & $2,4 \pm 0,46$ & $1,5 \pm 0,21$ & $3,1 \pm 0,32$ & $2,3 \pm 0,12$ \\
\hline каудальная доля & $2,1 \pm 0,30$ & - & $2,5 \pm 0,13$ & $1,8 \pm 0,21$ & - & $3,5 \pm 0,31$ & $1,3 \pm 0,5$ & - & $3,1 \pm 0,27$ \\
\hline Бронхиальные лимфатические узлы & - & - & $2,3 \pm 0,21$ & $0,1 \pm 0,03$ & - & $2,1 \pm 0,12$ & - & $2,1 \pm 0,09$ & $2,1 \pm 0,55$ \\
\hline Назофарингеальный смыв & - & - & $2,8 \pm 0,35$ & $2,1 \pm 0,25$ & - & $4,1 \pm 0,30$ & - & $2,2 \pm 0,55$ & $1,6 \pm 0,30$ \\
\hline Бронхотрахеальный смыв & - & - & $4,9 \pm 0,67$ & $2,5 \pm 1,30$ & - & $3,3 \pm 0,55$ & $0,3 \pm 0,21$ & $1,3 \pm 0,60$ & $2,1 \pm 0,58$ \\
\hline \multicolumn{10}{|l|}{ Слизистая оболочка: } \\
\hline трахеи & $0,5 \pm 0,03$ & - & - & - & - & - & - & - & - \\
\hline бронхов & $1,3 \pm 0,21$ & - & $2,3 \pm 0,39$ & $1,2 \pm 0,29$ & - & - & $0.3 \pm 0,21$ & - & - \\
\hline
\end{tabular}


Считается, что респираторно-синцитиальный вирус оказывает патогенетическое действие только на ранних стадиях инфекции и не обнаруживается или редко выявляется при колонизации легких бактериями и исчезает из них после транзитной инфекции (3, 6-9). Наши данные свидетельствуют о том, что BRSV присутствует в легких и в период их колонизации бактериями P. multocida и $M$. haemolytica.

Бактериологическая диагностика представляет собой трудоемкую процедуру, и ее эффективность зависит от многих факторов, включающих использование антибактериальных препаратов, соблюдение правил отбора проб биоматериала, эффект замораживания и оттаивания, а также присутствие микроорганизмов других видов в респираторных органах (1).

Использование метода РТ-ПЦР для выявления и количественного определения различных возбудителей у естественно инфицированных животных может быть полезно при изучении патогенеза моно- или смешанных инфекций in vivo. В доступной литературе мы не нашли результатов подобных исследований. Есть сообщения об определении концентрации вируса в носовых выделениях или бронхоальвеолярном лаваже у телят, экспериментально инфицированных высокопатогенными штаммами вируса в случае моноинфекции, однако об определении концентрации вируса у естественно инфицированных животных ранее не сообщалось (30-33). Имеются сообщения об одновременном обнаружении BRSV и других респираторных вирусов (34-35), BRSV и бактерий Histophilus somni (13), P. multocida, M. haemolytica и Trueperella pyogenes методом мультиплексной ПЦР (36), а также P. multocida и M. haemolytica иммуногистохимически (34). Однако количественную оценку этих вирусных и бактериальных агентов ранее также не проводили.

С помощью РТ-ПЦР мы смогли идентифицировать и определить количество двух бактерий в органах дыхательных путей обследованных телят, которое оказалось относительно низким. Неясно, является ли это следствием ограничений метода или связано со слабым размножением бактерий в тканях респираторного тракта в конкретный период времени.

Наши результаты показывают, что респираторно-синцитиальный вирус и бактерии семейства Pasteurellaceae могут размножаться в различных частях легких одновременно, не подавляя друг друга, чем подтверждается эффект их синергического взаимодействия $(1,4,14,16)$, а также взаимодействия M. haemolytica и $P$. multocida между собой, что приводит к усилению проявления клинических признаков и тяжести течения пневмонии у животных. Кроме того, по сравнению с бактериями вирус был обнаружен в более широком диапазоне проб биологического материала (назофарингеальный и бронхотрахеальный смывы, слизистая трахеи и бронхов, бронхиальные лимфатические узлы, краниальная, средняя и каудальная доли легких), отобранных от животных с признаками легочного пастереллеза. Нами также определена концентрация генома BRSV у естественно инфицированных животных и в более широком перечне респираторных органов, чем описано у экспериментально зараженных телят-гнотобионтов (30-33).

Итак, РТ-ПЦР позволила оценить распространение трех возбудителей в органах респираторного тракта больных телят в естественных условиях, а также определить концентрацию BRSV и бактерий Pasteurella multocida и Mannheimia haemolytica, которая варьировала соответственно от $0,1 \pm 0,03$ до $4,8 \pm 0,47 \log _{10}$ ГЭ/мл, от $1,3 \pm 0,60$ до $4,1 \pm 0,30 \log _{10}$ ГЭ/мл и от

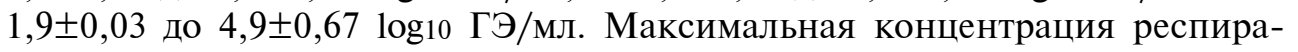
торно-синцитиального вируса BRSV была выявлена в легких, что указывает на преобладающий тропизм возбудителя к ткани этого органа. PT- 
ПЦР может быть полезным инструментом для изучения распространения и динамики размножения патогенов при смешанных вирусных и бактериальных инфекциях, а именно патогенеза и синергического взаимодействия возбудителей различных нозологических групп при заболеваниях органов дыхания крупного рогатого скота, в том числе при легочном пастереллезе. Кроме этого, наши результаты подчеркивают важность РТ-ПЦР как диагностического метода (с учетом слабой способности BRSV к размножению в культурах клеток и кратковременного «транзитного» характера инфекции).

\author{
ФГБУН Сибирский федеральный научный центр \\ агробиотехнологий РАН, Институт экспериментальной \\ ветеринарии Сибири и Дальнего Востока, \\ 630501 Россия, Новосибирская обл., Новосибирский р-н, \\ р.п. Краснообск, СФНЦА РАН, а/я 463, \\ e-mail: nav-vet@mail.ru, glotov_vet@mail.ru $₫$, koteneva-sv@mail.ru, \\ t-glotova@mail.ru
}

Поступила в редакцию

8 апреля 2021 года

Sel'skokhozyaistvennaya biologiya [Agricultural Biology], 2021, V. 56, № 4, pp. 695-706

\title{
DETECTION AND QUANTITATIVE ASSESSMENT OF VIRAL AND BACTERIAL PATHOGENS IN BOVINE RESPIRATORY DISEASES BY REAL-TIME-qPCR
}

\section{A.V. Nefedchenko, A.G. Glotov, S.V. Koteneva, T.I. Glotova}

Siberian Federal Scientific Center of Agro-BioTechnologies RAS, Institute of Experimental Veterinary Science of Siberia and the Far East, r.p. Krasnoobsk, PO box 463, Novosibirskii Region, Novosibirsk Province, 630501 Russia, e-mail navvet@mail.ru, glotov_vet@mail.ru (₫ corresponding author), koteneva-sv@mail.ru, t-glotova@mail.ru ORCID:

Nefedchenko A.V. orcid.org/0000-0002-4181-4268

Glotov A.G. orcid.org/0000-0002-2006-0196

The authors declare no conflict of interests

Received April 8, 2021

Koteneva S.V. orcid.org/0000-0003-2649-7505

Glotova T.I. orcid.org/0000-0003-3538-8749

doi: 10.15389/agrobiology.2021.4.695eng

\section{Abstract}

Bovine respiratory diseases are widespread in all countries with intensive animal husbandry and cause significant economic damage. They are the result of a synergistic interaction of several viruses and bacteria, predominantly of the Pasteurellaceae family. Clinical signs and pathological changes in internal organs depend on the presence or absence of a particular pathogen. Mass outbreaks occur when animals from different sources are mixed. The etiological structure of such outbreaks has been sufficiently studied, however, there is insufficient data on the distribution of bacteria and viruses in the respiratory tract and their quantitative determination. The article presents the results of studying the etiological structure of the outbreak of respiratory diseases in the big dairy farm after the import of cattle, during which more than 400 animals of different age and sex groups died. Samples of internal organs of 58 dead animals of different ages were examined. When studying the etiological structure of the outbreak, standard bacteriological methods were used, viral agents were identified by PCR by gel electrophoresis, and real-time PCR was used to quantify all detected infectious agents. In total, 9 viruses and bacteria were identified, of which the respiratory syncytial virus of cattle (BRSV, Bovine Respiratory Syncytial Virus, genus Pneumovirus, family Paramyxoviridae) and bacteria of the Pasteurellaceae family played a leading etiological role. Using quantitative PCR, the concentrations of the virus and bacteria Pasteurella multocida and Mannheimia haemolytica were determined in the respiratory tract organs of 13 calves of different ages with similar clinical signs, pathological changes and the presence of three pathogens in the respiratory tract organs. The concentration of agents ranged from $0.1 \pm 0.03$ to $4.8 \pm 0.47 \log _{10}$ genomic equivalents $(\mathrm{GE}) / \mathrm{ml}$ for $\mathrm{BRSV}$, from $1.3 \pm 0.60$ to $4.1 \pm 0.30 \log _{10} \mathrm{GE} / \mathrm{ml}$ for $P$. multocida, and from $1.9 \pm 0.03$ to $4.9 \pm 0.67 \log _{10} \mathrm{GE} / \mathrm{ml}$ for $M$. haemolytica. The concentration and distribution of pathogens in the organs of calves of different ages differed. BRSV was detected in a wider range of respiratory organs, both free from bacteria and colonized by them. In the lungs, the concentration of the virus was higher than in the tracheal and bronchial exudate. P. multocida was present only in the upper and middle lobes of the lungs of 2.5-4month-old calves at approximately equal concentrations in acute bronchopneumonia. The degree of colonization of the lungs by this bacterium increased with age and in calves at the age of 6 months its number reached maximum values in the upper and middle lobes of the lungs, pulmonary lymph nodes and washes from the mucous membranes in chronic bronchopneumonia. M. haemolytica was detected in acute bronchopneumonia in calves at the age of 2.5 months in a minimum amount in the middle 
lobes of the lungs, in a maximum amount in tracheal and bronchial exudates. The results showed that the virus and bacteria multiply in different parts of the lungs without suppressing each other, which confirms the effect of their synergistic interaction and leads to an increase in the severity of the course of pneumonia. Quantification of viruses and bacteria by real-time PCR can be a useful tool for studying the pathogenesis of mixed viral-bacterial infections in vivo. The results obtained underline the role of the BRSV in the development of pulmonary pasteurellosis.

Keywords: cattle, respiratory infections, real-time PCR, quantitative analysis, respiratory syncytial virus, Pasteurella multocida, Mannheimia haemolytica, synergism.

\section{R E F E R E N C ES}

1. Brogden K.A., Guthmiller J.M. Polymicrobial diseases. Washington, 2002.

2. Gorden P.J., Plummer P. Control, management and prevention of bovine respiratory disease in dairy calves and cows. Veterinary Clinics of North America: Food Animal Practice, 2010, 26(2): 243-259 (doi: 10.1016/j.cvfa.2010.03.004).

3. Andrews A.H., Blowey R., Boyd H., Eddy R. Respiratory disease. In: Bovine medicine: diseases and husbandry of cattle. A.N. Andrews, R. Blowey, H. Boyd, R. Eddy (ed.). Blackwell Scientific Publications, Oxford, 2004, 1232.

4. Fulton R.W., Purdy C.W., Confer A.W., Saliki J.T., Loan R.W., Briggs R.E., Burge L.J. Bovine viral diarrhea viral infections in feeder calves with respiratory disease: interactions with Pasteurella spp., parainfluenza-3 virus, and bovine respiratory syncytial virus. The Canadian Journal of veterinary Research, 2000, 64(3): 151-159.

5. Ackermann M.R., Brogden K.A. Response of the ruminant respiratory tract to Mannheimia (Pasteurella) haemolytica. Microbes and Infection, 2000, 2(9): 1079-1088 (doi: 10.1016/s12864579(00)01262-4).

6. Brodersen B.W. Bovine respiratory syncytial virus. Veterinary Clinics of North America: Food Animal Practice, 2010, 26(2): 323-333 (doi: 10.1016/j.cvfa.2010.04.010).

7. Larsen L.E. Bovine Respiratory Syncytial Virus (BRSV): a review. Acta Veterinaria Scandinavica, 2000, 41(1): 1-24.

8. Sacco R.E., McGill J.L., Pillatzki A.E., Palmer M.V., Ackermann M.R. Respiratory syncytial virus infection in cattle. Veterinary Pathology, 2014, 51(2): 427-436 (doi: 10.1177/0300985813501341).

9. Valarcher J.R., Schelcher R., Bourhy H. Evolution of bovine respiratory syncytial virus. Journal of Virology, 2000, 74(22): 10714-10728 (doi: 10.1128/jvi.74.22.10714-10728.2000).

10. Murray G.M., More S.J., Clegg T.A., Earley B., O’Neill R.G., Johnston D., Gilmore J., Nosov M., McElroy M.C., Inzana T.J., Cassidy J.P. Risk factors associated with exposure to bovine respiratory disease pathogens during the peri-weaning period in dairy bull calves. BMC Veterinary Research, 2018, 14: 53 (doi: 10.1186/s12917-018-1372-9).

11. Fulton R.W., d'Offay J.M., Landis C., Miles D.G., Smith R.A., Saliki J.T., Ridpath J.F., Confer A.W., Neill J.D., Eberle R., Clement T.J., Chase C.C., Burge L.J., Payton M.E. Detection and characterization of viruses as field and vaccine strains in feedlot cattle with bovine respiratory disease. Vaccine, 2016, 34(30): 3478-3492 (doi: 10.1016/j.vaccine.2016.04.020).

12. Sudaryatma P.E., Nakamura K., Mekata H., Sekiguchi S., Kubo M., Kobayashi I., Subangkit M., Goto Y., Okabayashi T. Bovine respiratory syncytial virus infection enhances Pasteurella multocida adherence on respiratory epithelial cells. Veterinary Microbiology, 2018, 220: 33-38 (doi: 10.1016/j.vetmic.2018.04.031).

13. Agnes J.T., Zekarias B., Shao M., Anderson M.L., Gershwin L.J., Corbeil L.B. Bovine respiratory syncytial virus and Histophilus somni interaction at the alveolar barrier. Infection and Immunity, 2013, 81: 2592-2597 (doi: 10.1128/IAI.00108-13).

14. Singh K.J., Ritchey W., Confer A.W. Mannheimia haemolytica: bacterial-host interactions in bovine pneumonia. Veterinary Pathology, 2011, 48(2): 338-348 (doi: 10.1177/0300985810377182).

15. Tizioto P.C., Kim J., Seabury C.M., Schnabel R.D., Gershwin L.J., Van Eenennaam A.L., ToaffRosenstein R., Neibergs H.L., Taylor J.F. Immunological response to single pathogen challenge with agents of the bovine respiratory disease complex: an RNA-Sequence analysis of the bronchial lymph node transcriptome. PLOS ONE, 2015, 10(6): e0131459 (doi: 10.1371/journal.pone.0131459).

16. Rice J.A., Carrasco-Medina L., Hodgins D.C., Shewen P.E. Mannheimia haemolytica and bovine respiratory disease. Animal Health Research Reviews, 2007, 8(2): 117-128 (doi: 10.1017/S1466252307001375).

17. Glotov A.G., Glotova T.I., Nekrasova N.V., Nefedchenko A.V., Goppe V.A. Veterinariya, 2005, 11: 20-23 (in Russ.).

18. Glotov A.G., Glotova T.I., Nefedchenko A.V., Grebennikova T.V., Alipper T.I. Veterinariya, 2007, 12: 27-29 (in Russ.).

19. Vilcek S., Elvander M., Ballagi-Pordany A., Bleak S. Development of nested PCR assays for detection of bovine respiratory syncytial virus in clinical samples. Journal of Clinical Microbiology, 1994, 32(9): 2225-2231 (doi: 10.1128/JCM.32.9.2225-2231.1994). 
20. Horwood P.F., Gravel J.L., Mahony T.J. Identification of two distinct bovine parainfluenza virus type 3 genotypes. Journal of General Virology, 2008, 89(7): 1643-1648 (doi: 10.1099/vir.0.2008/000026-0).

21. Takiuchi E., Stipp D.T., Alfieri A.F., Alfieri A.A. Improved detection of bovine coronavirus $N$ gene in faces of calves infected naturally by a semi-nested PCR assay and an internal control. Journal of Virological Methods, 2006, 13(2): 148-154 (doi: 10.1016/j.jviromet.2005.08.005).

22. OIE. Manual of Diagnostic Tests and Vaccines for Terrestrial Animals, 8th Edition. Paris, France, 2018.

23. Nefedchenko A.V., Shikov A.N., Glotov A.G., Glotova T.I., Ternovoi V.A., Agafonov A.P., Sergeev A.N., Donchenko N.A. Molekulyarnaya genetika, mikrobiologiya i virusologiya, 2016, 34: 62-66 (doi: 10.18821/0208-0613-2016-34-2-62-66) (in Russ.).

24. Subramaniam S., Bergonier D., Poumarat F. Species identification of Mycoplasma bovis and Mycoplasma agalactiae based on the urvC genes by PCR. Molecular and Cellular Probes, 1998, 12(3): 161-169 (doi: 10.1006/mcpr.1998.0160).

25. Angen Ø., Ahrens P., Tegtmeier C. Development of a PCR test for identification of Haemophilus somnus in pure and mixed cultures. Veterinary Microbiology, 1998, 63(1): 39-48 (doi: 10.1016/S0378-1135(98)00222-3).

26. Boxus M., Letellier C., Kerkhofs P. Real time RT-PCR for the detection and quantitation of bovine respiratory syncytial virus. Journal of Virological Methods, 2005, 125(2): 125-130 (doi: 10.1016/j.jviromet.2005.01.008).

27. Zhao H., Liu J., Li Y., Yang C., Zhao S., Liu J., Liu A., Liu G., Yin H., Guan G., Luo J. Validation of reference genes for quantitative real-time PCR in bovine PBMCs transformed and non-transformed by Theileria annulata. Korean Journal of Parasitology, 2016, 54(1): 39-46 (doi: $10.3347 / \mathrm{kjp} .2016 .54 .1 .39$ ).

28. Nefedchenko A.V., SHikov A.N., Glotov A.G., Glotova T.I., Ternovoi V.A., Maksyutov R.A., Agafonov A.P., Sergeev A.N. Detection and genotyping Pasteurella multocida of five capsular groups in real time polymerase chain reaction. Sel'skokhozyaistvennaya biologiya [Agricultural Biology], 2017, 52(2): 401-408 (doi: 10.15389/agrobiology.2017.2.401eng).

29. Jordan R., Shao M., Mackman R.L., Perron M., Cihlar T., Lewis S.A., Eisenberg E.J., Carey A., Strickley R.G., Chien J.W., Anderson M.L., McEligot H.A., Behrens N.E., Gershwin L.J. Antiviral efficacy of an RSV fusion inhibitor in a bovine model of RSV infection. Antimicrobial Agents and Chemotherapy, 2015, 59(8): 4889-4900 (doi: 10.1128/AAC.00487-15).

30. Antonis A.F.G. Age-dependent differences in the pathogenesis of bovine respiratory syncytial virus infections related to the development of natural immunocompetence. Journal of General Virology, 2010, 91(10): 2497-2506 (doi: 10.1099/vir.0.020842-0).

31. Blodörn K., Hägglund S., Gavier-Widen D., Eléouët J.F., Riffault S., Pringle J., Taylor G., Valarcher J.F. A bovine respiratory syncytial virus model with high clinical expression in calves with specific passive immunity. BMC Veterinary Research, 2015, 11: 76 (doi: 10.1186/s12917-0150389-6).

32. Thomas L.H., Slott E.J., Collins A.P., Jebbett J. Experimental pneumonia in gnotobiotic calves produced by respiratory syncytial virus. British Journal of Experimental Pathology, 1984, 65: 19-28.

33. Tjørnehøj K., Uttenthal A., Viuff B., Larsen L.E., Røntved C., Rønsholt L. An experimental infection model for reproduction of calf pneumonia with bovine respiratory syncytial virus (BRSV) based on one combined exposure of calves. Research in Veterinary Science, 2003, 74(1): 55-65 (doi: 10.1016/s0034-5288(02)00154-6).

34. Yaman T., Büyükbayram H., Özyıldız Z., Terzi F., Uyar A., Keles Ö.F., Özsoy ş.Y., Yener Z. Detection of bovine respiratory syncytial virus, Pasteurella multocida, and Mannheimia haemolytica by immunohistochemical method in naturally-infected cattle. Journal of Veterinary Research, 2018, 62(4): 439-445 (doi: 10.2478/jvetres-2018-0070).

35. Thonur L., Maley M., Gilray J., Crook T., Laming E., Turnbull D., Nath M., Willoughby K. One-step multiplex real time RT-PCR for the detection of bovine respiratory syncytial virus, bovine herpesvirus 1 and bovine parainfluenza virus 3. BMC Veterinary Research, 2012, 8: 37 (doi: 10.1186/1746-6148-8-37).

36. Zhang W., Liu X., Liu M., Ma B., Xu L., Wang J. Development of a multiplex PCR for simultaneous detection of Pasteurella multocida, Mannheimia haemolytica and Trueperella pyogenes. Acta Veterinaria Hungarica, 2017, 65(3): 327-339 (doi: 10.1556/004.2017.032). 